\title{
Software de Apoio à Alfabetização de crianças com Necessidades Especiais
}

\author{
Literacy Software Support for Children's with Special Needs
}

\section{Fábio Marcos Euzébio ${ }^{1}$}

\author{
Bruno Fernandes ${ }^{1,2}$ \\ ${ }^{1}$ Escola Politécnica de Pernambuco, Universidade de Pernambuco, Recife, Brasil. \\ 2 Pós-graduação em Engenharia de Sistemas, Escola Politécnica de Pernambuco, Pernambuco, Brasil. \\ E-mail do autor principal: Fábio Euzébio fabiomarcoseuzébio@gmail.com
}

\section{Resumo}

O trabalho de alfabetização de crianças com necessidades especiais é algo que exige muito esforço e dedicação devido à complexidade e variação dos graus de dificuldade que uma criança especial pode apresentar. Por isso, escolas específicas e profissionais com formação diferenciada são necessários para atender a essa necessidade. O objetivo deste artigo é descrever o processo de desenvolvimento de um software educacional que auxilia na alfabetização de crianças com necessidades especiais. O software é destinado ao ensino de língua portuguesa (brasileira) podendo ser utilizado tanto em instituições de ensino regular quanto especializada. A partir da coleta de materiais e da observação dos métodos utilizados no dia a dia pelos profissionais de educação, foi possível levantar os requisitos e parâmetros necessários para sua elaboração. Com o uso adequado de uma ferramenta de apoio no processo de alfabetização, além de reduzir significativamente o tempo para alfabetizar uma criança especial, pode-se treinar sua coordenação motora e melhorar seus níveis de concentração. A utilização de um meio digital e informatizado no processo de alfabetização tem como principal vantagem capturar a atenção da criança ao mesmo tempo em que torna-se desafiadora, fazendo com que a memorização de letras e formação de palavras mostre seus resultados em um espaço de tempo menor do que o necessário, caso a alfabetização fosse realizada utilizando-se apenas meios convencionais.

Palavras-Chave: Educação especial; Alfabetização; Informática; Necessidades especiais;

\begin{abstract}
The work of children with special needs literacy is something that requires a lot of effort and dedication due to the complexity and variation of the degrees of difficulty that a special child can present. Therefore, specific schools and professionals with differentiated training are needed to meet this need. The purpose of this article is to describe the process of developing an educational software to assist in the literacy of children with special needs in the Portuguese language of Brazil, and can be used in any educational institution, regular or specialized. From the collection of materials and the observation of the methods used in daily life by education professionals, it was possible to raise the requirements and parameters necessary for the elaboration of the software. With the proper use of a support tool in the literacy process, it can significantly reduce the time it takes to literate a special child, as well as train their motor coordination and improve their concentration levels. The use of a digital and computerized means in the literacy process has the main advantage of capturing the attention of the child while it becomes challenging, causing the memorization of letters and word formation to show their results in a period lower than necessary, if literacy were to be achieved using only conventional ways.
\end{abstract}

Key-words: Child; Literacy; Computer science; special needs; disability; teaching. 


\section{Introdução}

A tecnologia motiva transformações na vida da sociedade com todos os seus recursos. É uma ferramenta importante na formação do indivíduo, estimulando-o a pensar sobre os diversos processos educativos. Com isso surgem novos ambientes de aprendizagem e com eles a oportunidade de rever o formalismo acadêmico e a relação professor/aluno.

O ensino através de instrumentos tecnológicos busca superar tempo e espaço, estimulando o aluno a ter novas experiências de aprendizagem aprimorando seus conhecimentos e dando sequência aos estudos. Essas ferramentas são indispensáveis na busca pela eficiência educacional, visto que a educação passa por um processo de renovação, com as mudanças ocorridas na sociedade. (SAHB [1]).

Dessa forma, em escolas especiais, é crucial que a didática seja aprimorada em relação à didática tradicional e 0 uso de softwares educacionais torna-se um grande aliado nesse processo de ensino.

Mesmo com programas educacionais, é grande a falta de regras para orientar professores e pais. Por isso, a escolha do software educacional é complexa por envolver fatores pedagógicos e de integração na educação especial.

De acordo com Warlley Ferreira Sahb (SAHB [1]), o termo "criança especial", público alvo desse artigo, não se limita apenas à crianças com limitações externas como paralisia, surdez, cegueira, e limitações físicas. Englobam-se crianças que, devido a algum distúrbio, apresentam dificuldades no aprendizado escolar e por isso, são inseridas dentro do contexto de escolas com profissionais preparados para atendê-las.

A utilização de um software educacional para auxílio na alfabetização dessas crianças, tem como objetivo tornar-se uma ferramenta adicional aos recursos convencionais que já são utilizados no dia-a-dia pelos profissionais educadores.

O objetivo desse estudo é descrever o processo de desenvolvimento de um software de apoio à alfabetização de crianças com necessidades especiais.

\section{O Papel da Informática na Educação Especial}

Diante da grande quantidade de crianças com dificuldades de aprendizado, existe a necessidade de adaptá-las às escolas. Crianças com dificuldades de aprendizado podem tanto comprometer o aprendizado de outras quanto ser esquecida. Devido a estes problemas, são criadas escolas para atenderem crianças com dificuldade de aprendizado. (SAHB [1])

As escolas especiais buscam oferecer à criança especial um meio de serem alfabetizadas sem comprometer suas limitações. As ferramentas que possam despertar o raciocínio e facilitar na interação do professor com os alunos são importantes, e geram grande contribuição na alfabetização.

O computador é uma ferramenta que pode gerar novo tipo de aprendizagem, permitindo que o aluno de passivo passe a ser o autor da construção, com o desenvolvimento envolvendo descrição, execução, reflexão e depuração. (MARINHO[2]).

Devido às necessidades na alfabetização de crianças especiais, o uso de ferramentas computacionais pode tornar-se necessário para auxiliar e suprir as dificuldades por distúrbio ou dificuldades gerais.

O uso dessas ferramentas em escolas especiais também tem sido válido para aguçar a atenção dos alunos e facilitar a captação de informações, onde o aluno passa a aprender de forma dinâmica e diferente. O uso do software educacional pode tornar-se um grande aliado no processo da alfabetização especial.

As apresentações de exercícios e tarefas permitem a eficiência do ensino computadorizado, tendo ainda como benéficos os registros automáticos e a independência por parte dos alunos facilitando a análise $e$ interpretação dos resultados. A proposta é ensinar através de um software educacional e desta forma, ilustrar o potencial dos computadores para o processo ensino- 
aprendizagem (GOYOS; ALMEIDA Apud SILVA; MEDEIROS [3]).

O aprendizado precisa ocorrer em um ambiente agradável e atrativo aos educandos, respeitando os diferentes raciocínios, singularidade e habilidades próprias de cada etapa do desenvolvimento humano.

Os softwares precisam estimular o raciocínio e motivar a criança a aprender. Educacionalmente é preciso que na brincadeira o professor envolva os conhecimentos ou jogos mais adequados à prática pedagógica.

Dessa forma, o professor propicia aos alunos a socialização, a criatividade e imaginação, a memória, a atenção e o autoconhecimento, promovendo autoestima e a prática de relacionamento social.

\section{Softwares Educacionais}

$\mathrm{Na}$ aprendizagem utilizando os meios computacionais, os softwares devem possuir características que propiciem atividades onde os alunos apliquem processos para 0 desenvolvimento do conhecimento, enfatizando o saber "aprender a aprender".

O trabalho com o software educacional deve ser desenvolvido de forma que o aluno seja capaz de responder ao que the é solicitado e assim, juntamente com a aplicação da tecnologia, estruturar a sequência do ensino.

Para atingir e superar esses objetivos, o software deve estar vinculado a essas necessidades, sendo importante fazer uma avaliação antes de trabalhar com as crianças.

De acordo com o trabalho realizado com crianças de diferentes graus de deficiência, aplicado por Rosária Maria Fernandes da Silva[4], psicóloga e pedagoga, chegou-se à conclusão que, utilizando-se um método onde a criança era estimulada a realizar um pareamento entre uma imagem mostrada na tela do computador e sua respectiva palavra (método de equivalência), os índices de aprendizado eram enriquecidos. Ao final do trabalho, notou-se um grau de progresso substancial em todas as crianças que participaram da experiência, independente do seu grau de deficiência.

\section{Metodologia}

Baseando-se nos dados coletados e pesquisados, o software proposto tem o objetivo de reproduzir o material utilizado em sala de aula tendo o dispositivo computacional como uma ferramenta aliada à captura da atenção da criança e produzindo um ambiente desafiador no qual o educando é estimulado e elogiado pelo professor orientador cada vez que obtém êxito.

Adicionalmente, foi analisado o trabalho publicado por Flávio Cezar Amate[5], que consiste em um jogo de computador construído utilizando a ferramenta de desenvolvimento "Delphi 7", cuja linguagem de programação, na época em que seu trabalho foi elaborado, era uma excelente plataforma de desenvolvimento para sistemas operacionais Windows 32 bits (Microsoft Windows[6]).

O objetivo principal desse jogo, era promover a alfabetização e o conhecimento de palavras simples. Devido às limitações impostas por esse ambiente de desenvolvimento, o projeto tornouse incompatível com as plataformas e sistemas operacionais atuais impedindo seu uso e tornando-o obsoleto. Seu objetivo principal, porém, serviu de modelo e guia para vários pontos desse estudo.

Na elaboração desse novo projeto, a interface e a interação com o usuário foram considerados como elementos de alta importância devido ao contexto onde o software será utilizado devido às características únicas que envolvem o processo de alfabetização na Língua Portuguesa do Brasil, foram excluídos desse trabalho, artigos e softwares de outras línguas.

\section{Estudos de Caso}

\section{Caso 1}

Para coleta de dados e início da análise, foi feita uma visita à Escola Cecília Meireles, localizada na cidade de Maceió-AL.

Durante essa visita, realizada em outubro/2016 com duração de um dia inteiro, realizou-se uma entrevista aberta com a diretora e psicopedagoga que contou a história da instituição, seu modo de trabalho e sua importância no bairro onde atua. Em seguida, foi http: / /dx.doi.org/10.25286/repa.v3i2.551 
acompanhado o trabalho de uma das coordenadoras e observado o comportamento das crianças com necessidades especiais.

Para fins de ilustração, obteve-se na internet a representação, em forma de figuras, dos materiais envolvidos no desenvolvimento das atividades.

A "Figura 1", mostra os cartões que são utilizados pelos pedagogos para memorização das letras correspondendo com a figura que as representam. São usadas palavras simples e de fácil entendimento. O uso de cores também é fator importante não apenas para auxiliar a memorização como também para capturar a atenção da criança.O título deve definir em poucas palavras os conceitos chaves do seu manuscrito.

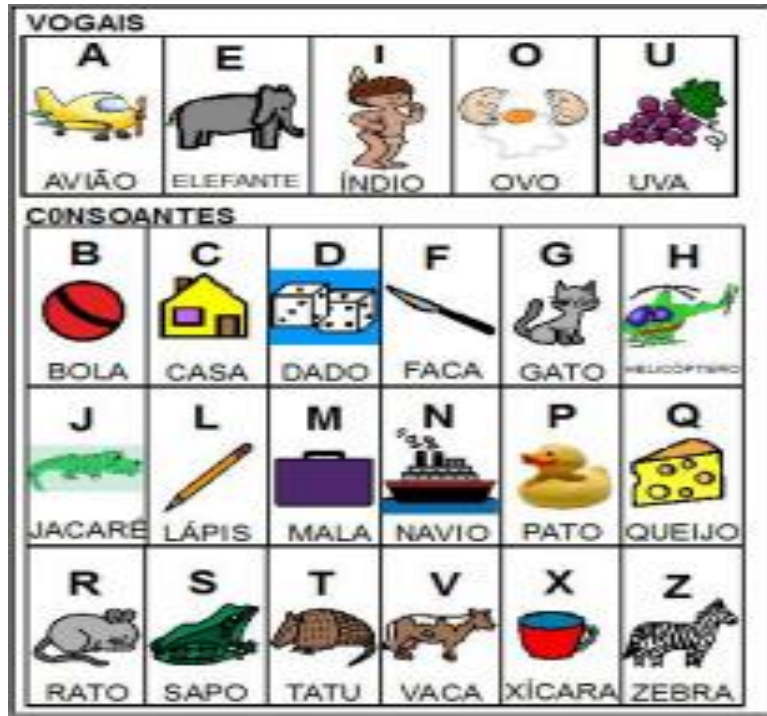

Figura 1: Cartela de cartões com figuras e palavras simples.

Fonte: Os autores.

A "Figura 2" exemplifica cartões prontos para uso. As frases são um pouco mais complexas e podem referir-se a ações, partes do corpo, sentimentos e outras expressões utilizadas no dia-a-dia. Esse material é geralmente utilizado com crianças portadoras de um grau menor de limitações.

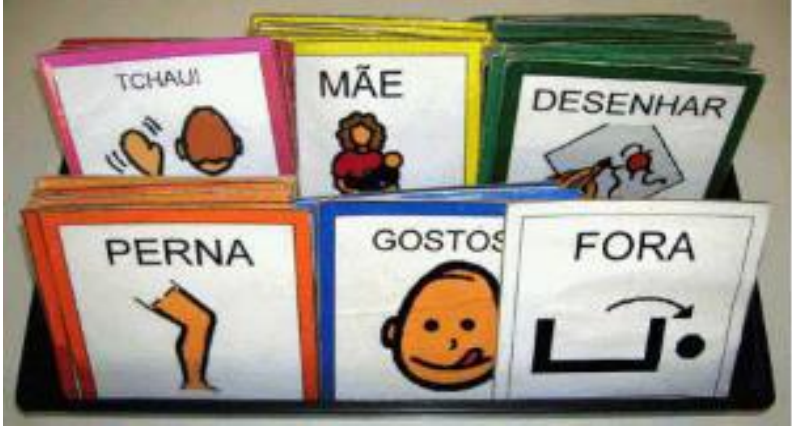

Figura 2: Cartões utilizados para associação de frases com ações, gestos, etc.

Fonte: Os autores.

A utilização desses materiais é feita de forma simples, o educador repete várias vezes a palavra para a criança ao mesmo tempo em que aponta para a figura correspondente, chamando a atenção para a letra em destaque.

O método de alfabetização utilizando-se esses materiais é feito de forma repetitiva preparando o aluno para memorizar a junção das consoantes com suas vogais e como consequência natural, formar novas palavras.

\section{Caso 2}

Em uma entrevista com a profissional de pedagogia, Sra Marilene Maria de Melo, 15 anos de profissão, possui curso de libras e sempre trabalhou com crianças com necessidades especiais, foi aplicado um questionário previamente elaborado de onde foram levantadas as informações a seguir.

$\mathrm{Na}$ sala de aula, onde a pedagoga exerce sua função, existem 3 crianças portadoras de necessidades especiais.

A maior dificuldade percebida pela profissional é que nem todas as crianças podem ser alfabetizadas plenamente, devido ao fato de terem estudado anteriormente em escolas que não possuíam estruturas ou profissionais adequados ao atendimento apropriado para essas crianças.

Dependendo do caso, uma criança com necessidades especiais leva de 1 a 2 anos para ser alfabetizada mediante utilização dos materiais disponíveis.

Alguns dos materiais utilizados atualmente pela profissional foram fotografados e apresentados abaixo nas figuras 3,4 e 5 . 
O estojo com material em forma de bastões e blocos, é confeccionado em madeira e pintado com cores diferentes e utilizado na aprendizagem de noções de grandezas (Figura 3).

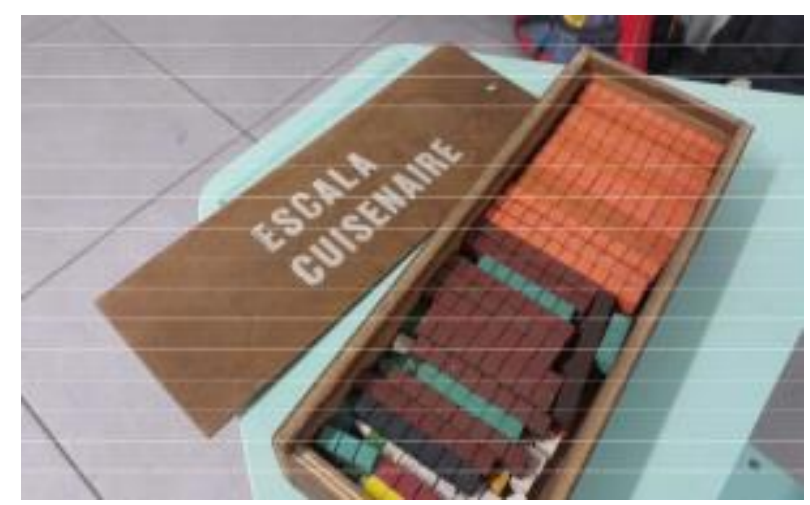

Figura 3: Material para estudo de grandezas. Fonte: Os autores.

O ábaco é fabricado com material de plástico rígido e serve para treinar raciocínio lógico e fazer contas simples (Figura 4).

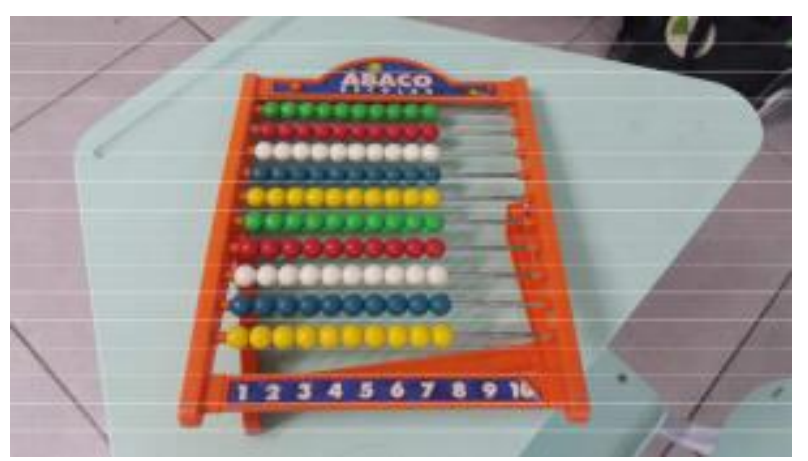

Figura 4 :Ábaco para simples realização de contas. Fonte: Os autores.

$\mathrm{Na}$ sala existe um mural com todas as letras do alfabeto. Confeccionado em papel, exibe uma imagem com a sua letra correspondente (Figura 5)

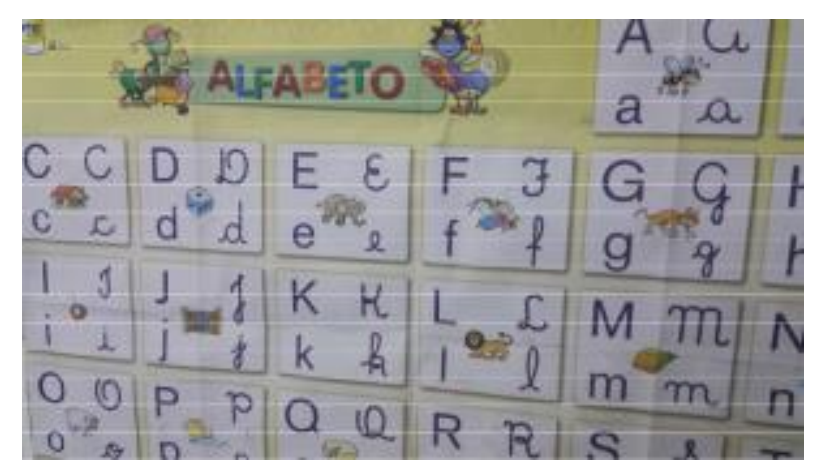

Figura 5: Material de auxílio à memorização das letras. Fonte: Os autores.
Os alunos com necessidades especiais dividem o mesmo ambiente da sala de aula com as outras crianças. Apenas em período de provas e avaliações é que eles são conduzidos para outro ambiente onde realizam atividades específicas.

A convivência de alunos com necessidades especiais e os demais alunos dentro do mesmo ambiente propicia, segundo a educadora, o desenvolvimento de sua socialização através da interação e brincadeiras com os colegas de turma. Além disso essa convivência proporciona a educação de todos para que seja desenvolvido um convívio sadio e respeitoso quanto às diferenças e limitações do próximo.

A instituição de ensino não faz uso de nenhum recurso computacional no auxílio da alfabetização dessas crianças, apesar de haver um profundo interesse da profissional em utilizar a informática como instrumento de apoio no processo de alfabetização. Devido à escassez de softwares voltados especificamente para área de crianças especiais, a profissional faz uso dos materiais existentes ou cria outros com material reciclado.

Ainda de acordo com a profissional, o maior impacto no processo de alfabetização das crianças com necessidades especiais utilizandose ferramentas computacionais, seria a redução do tempo de alfabetização e o desenvolvimento expressivo da coordenação motora.

\section{Estudo de Viabilidade}

Foram considerados aspectos relacionados à viabilidade operacional do software e à viabilidade técnica.

\subsection{Viabilidade técnica}

Com a popularização de diversas linguagens de programação voltadas para o ambiente web, 0 projeto pode ser desenvolvido utilizando-se plataformas de código livre, ou plataformas proprietárias.

Por ter funcionamento simples, a linguagem de programação e sua plataforma não se apresentam como obstáculos. 


\subsection{Viabilidade operacional}

Com a utilização de um software pelo profissional de educação, espera-se reduzir o tempo que se leva para alfabetizar uma criança com necessidades especiais que, de acordo com uma das entrevistadas, varia de 1 a 2 anos considerando o uso de materiais comuns. O processo de desenvolvimento do software deve atender à estrutura PIECES que é parte do estudo da viabilidade operacional.

\subsection{Estrutura de Peices}

Pieces é uma sigla caracterizada por seis questões que devem ser levadas em consideração durante 0 processo de desenvolvimento de um software. Essa técnica traz, de maneira estruturada, os problemas que devem ser observados.

a) Desempenho : devido à natureza do projeto, a performance do sistema poderá se adequar a qualquer tipo de equipamento, desde os mais modernos até os mais antigos sem danos à sua execução;

b) Informação: As informações das figuras e frases que irão compor cada exercício, ficarão armazenadas em um banco de dados e só poderão ser acessadas pela aplicação;

c) Economia: O software será desenvolvido e distribuído de acordo com as regras do software livre sem custo algum para o utilizador;

d) Controle: Não existem necessidades especiais de controle de furto ou fraude das informações.

e) Eficiência: O software, dentre outras coisas, procura capturar a atenção do aluno que está executando o exercício, bem como garantir que todo o processo seja conduzido de forma simples pelo educador;

f) Serviços: O software poderá ser utilizado e modificado sem restrições, desde que sejam mantidas as suas características e objetivos e que seja utilizado livremente.

\section{SuperAlfa}

O nome sugerido para o software é "SuperAlfa", que remete à palavra "superação" e também à ação de "alfabetizar". Foi desenvolvido um protótipo demonstrando os recursos diponíveis nesse estudo e disponibilizado para download no sítio:

\section{https://sourceforge.net/projects/superalfa/}

\subsection{Requisitos}

Os requisitos funcionais, descrevem as funcionalidades do sistema, como ele deve reagir a entradas de dados, e seu comportamento em determinadas situações.

Os requisitos não-funcionais, estão relacionados ao uso do software em termos de desempenho, usabilidade, segurança e tecnologias envolvidas.

No processo de desenvolvimento do software levantou-se os requisitos abaixo.

\subsection{1 - Funcionais}

a) O nome do aluno tem que ser obrigatório;

b) O campo de idade do aluno só poderá receber números;

c) A idade do aluno será informada em anos;

d) É obrigatória a seleção de uma atividade;

e) O sistema deverá contar a quantidade de erros e acertos da atividade;

f) O sistema deverá apresentar, no final de cada atividade, o nome do aluno sua idade a data e hora atual e o quantitativo de erros e acertos;

g) O sistema deverá ter a opção de impressão do resultado para que o documento possa ser avaliado por outros profissionais ou arquivado. 


\subsection{2 - Não funcionais}

a) O professor orientador poderá operar o sistema após um breve treinamento;

b) As figuras apresentadas deverão ser coloridas e ter o mesmo padrão de tamanho;

c) As fontes utilizadas nos textos das palavras deverão ser grandes e monoespaçada;

d) A plataforma de desenvolvimento será WEB.

\subsection{Diagrama de atividades}

O diagrama de atividades mostra o fluxo de controle do software de acordo com o projeto do seu funcionamento. Esse fluxo pode ser visto na "Figura 6" abaixo:

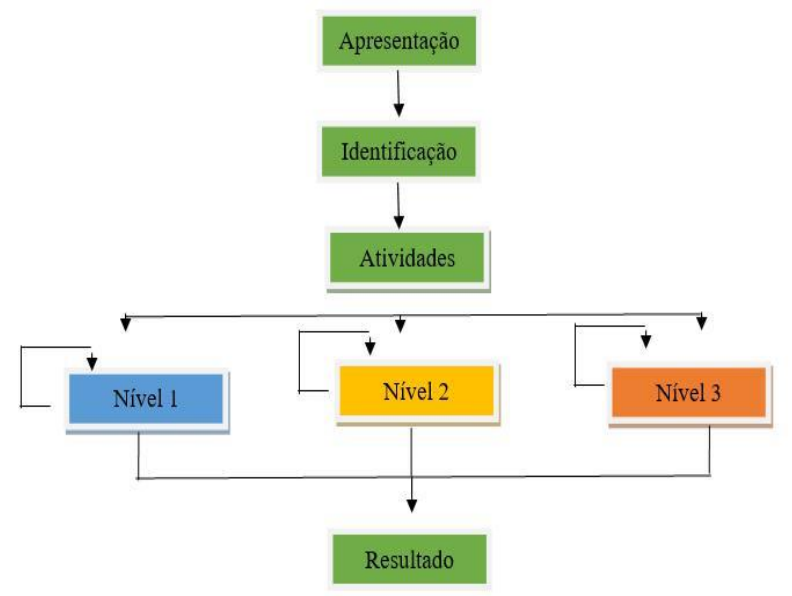

Figura 6: Diagrama de atividades. Fonte: Os autores.

\subsection{Diagrama de classes}

O diagrama de classes é uma modelagem útil para o desenvolvimento de um sistema, pois define as classes que sistema precisa possuir e serve como base para elaboração de outros diagramas.

A "Figura 7", apresenta a estrutura e relações entre as classes utilizadas no projeto do software.

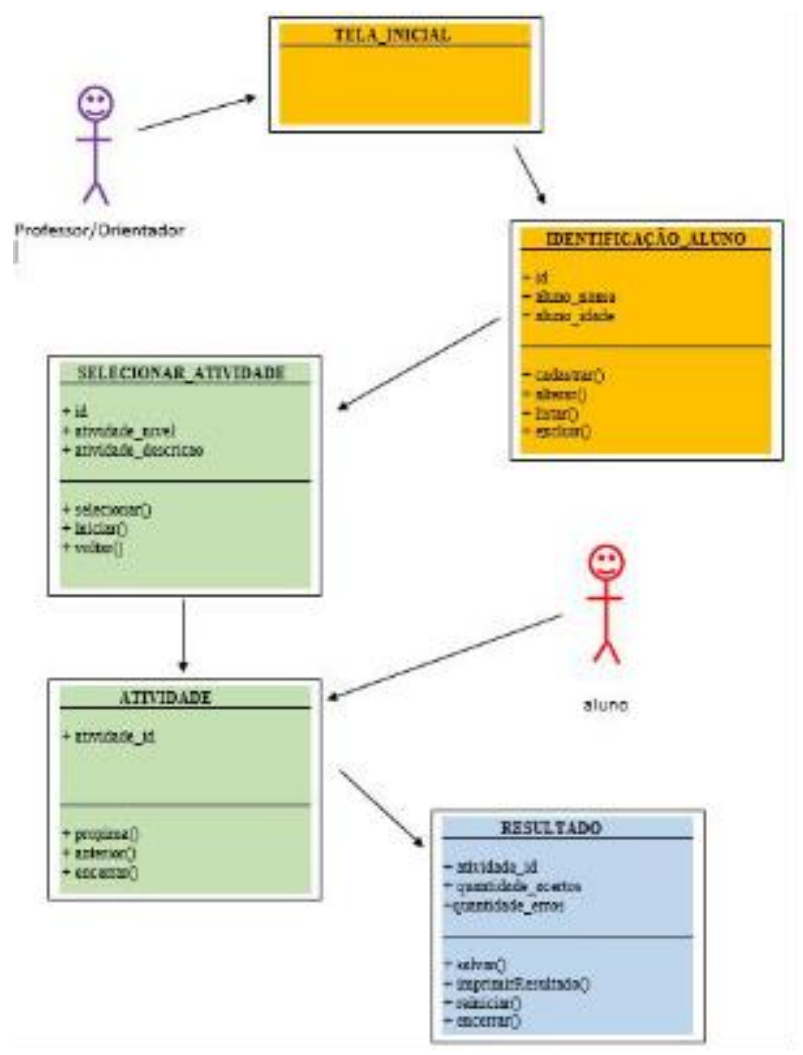

Figura 7 : Diagrama de classes.

Fonte: Os autores.

\subsection{Interface}

De acordo com Rocha e Baranauskas [7] não se pode pensar em interface sem considerar o ser humano que vai usá-la e, portanto, interface e interação são conceitos que não podem ser analisados separadamente.

A elaboração das telas do software são baseadas nas dez heurísticas de Jackob Nielsen [8].

1) Visibilidade de qual estado o sistema se encontra

As disposições das figuras e opções devem ser apresentadas de forma clara e simples de modo que o aluno e o educador sempre estejam cientes de suas ações dentro do software;

2) Falar a linguagem do usuário

A linguagem, palavras e opções devem ser simples e claras sem o uso de termos técnicos;

3) Liberdade e controle fácil para o usuário http: / / dx.doi.org/10.25286/repa.v3i2.551 
O aluno e o educador devem ter liberdade para fazer o que quiserem dentro do sistema obedecendo as regras de negócio que compõem o seu funcionamento;

\section{4) Consistência e padrão}

O software deve manter o mesmo padrão de suas telas, evitando adicionar elementos diferentes para as mesmas finalidades;

\section{5) Prevenção de erros}

Manter o modelo de navegação simples, de forma que o aluno ou educador consiga realizar suas funções facilmente e sem necessidade de memorização;

\section{6) Reconhecimento em vez de memorização}

Evitar que seja preciso utilizar-se da memória para executar alguma tarefa, a interface precisa fornecer informações que sejam capazes de orientar cada ação;

7) Eficiência de uso

O software precisa ser de fácil entendimento e uso, principalmente em se tratando do contexto onde será utilizado e as limitações que uma criança especial possui;

8) Diálogos simples e naturais

Os diálogos de mensagens do software precisam ser simples e funcionais, presentes apenas nos momentos em que são realmente necessários;

9) Boas mensagens de erro

As mensagens de erro, quando houver, devem ser simples e diretas, ajudando o usuário a entender o problema e encontrar a solução;

\section{0) Documentação}

O ideal é que não seja necessário ter uma documentação. O software deve ser simples, fácil e intuitivo o suficiente para que seu uso não dependa de uma documentação específica.

\subsection{Prototipação}

A prototipação do software tem como finalidade ajudar a entender o seu propósito, funcionamento, entender os requisitos, apresentar os conceitos e sua funcionalidade.

Para atingir esse objetivo, foi usado o programa livre "Pencil Project [9]" que pode ser instalado em qualquer plataforma, baixado diretamente do sítio do desenvolvedor.

As telas do protótipo são apresentadas nas figuras $8,9,10,11,12$ e 13 .

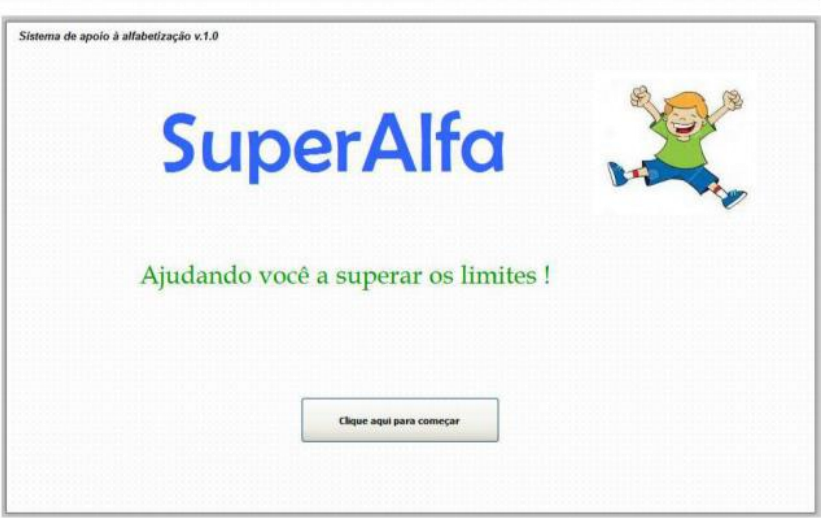

Figura 8: Tela Inicial.

Fonte: Os autores.

Na tela seguinte, chamada de "identificação", serão fornecidos os dados do aluno (seu nome e idade) e o nome do profissional que irá aplicar a atividade. Essa tela está ilustrada na "Figura 9".

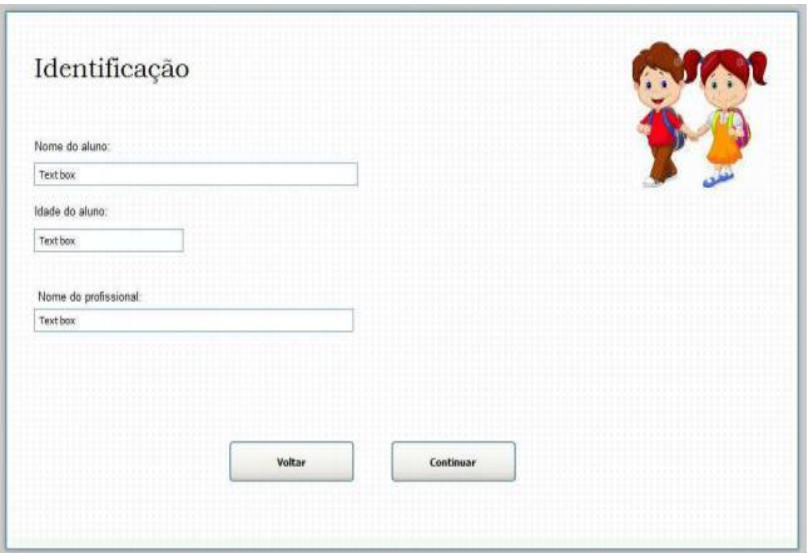

Figura 9: Tela de Identificação.

Fonte: Os autores. 
A "Figura 10" ilustra a tela onde é informada a quantidade de palavras que irão compor a atividade. Essa quantidade será determinada pelo educador de acordo com o nível de interesse do aluno. Um número muito grande de palavras pode fazer com que ele perca o interesse pela atividade.

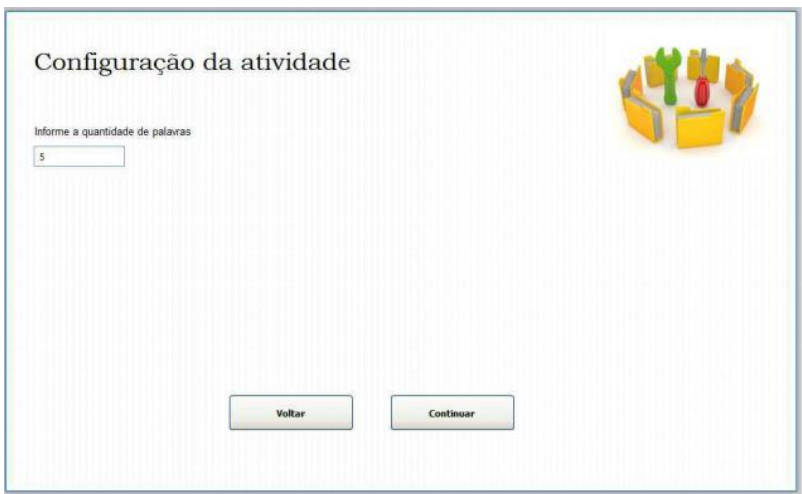

Figura 10: Configuração da quantidade de imagens que irão compor a atividade.

Fonte: Os autores.

Na tela ilustrada pela "Figura 11 ", o educador informará o nível da atividade a ser executada. A decisão sobre essa informação é baseada no processo de desenvolvimento do aluno avaliado pelo seu educador. Cada nível é definido da seguinte forma:

Nível I - Memorização

Palavras são exibidas aleatoriamente (uma de cada vez) juntamente com a sua imagem correspondente. $\mathrm{O}$ objetivo desse exercício é a memorização da letra inicial da palavra, destacando-a com uma cor diferente;

Nível II - Treinamento

Palavras são exibidas aleatoriamente com a imagem sem a letra correspondente para que o aluno possa identificá-la em um grupo de 3 letras aleatórias;

Nivel III - Teste

Apenas a imagem será exibida para que o aluno, utilizando um dispositivo apontador ou mesmo um teclado, forme a palavra completa;

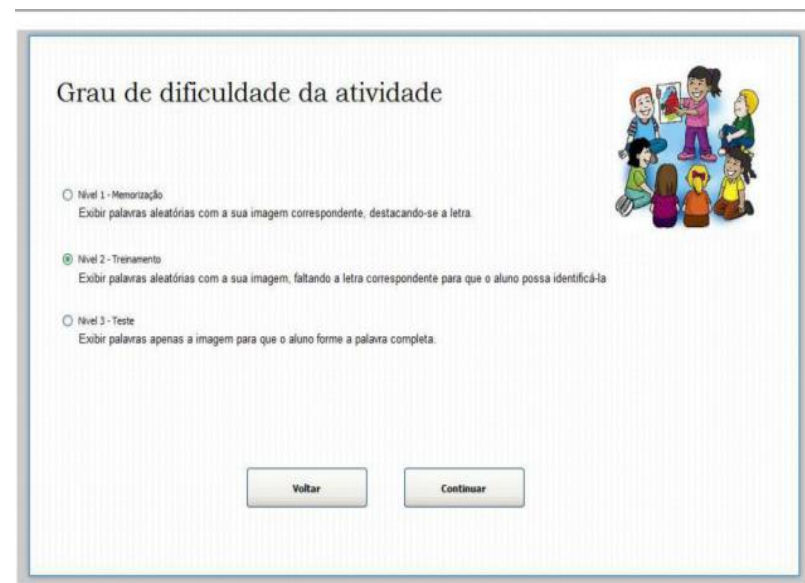

Figura 11: Tela de seleção do nível da atividade a qual o aluno participará.

Fonte: Os autores.

Após o preenchimento e configuração de todas as informações, o aluno poderá iniciar a atividade.

A "Figura 12" ilustra a atividade de nível 2 sendo executada onde é exibida uma figura e parte da palavra que a representa. O aluno, então, deverá escolher a letra que a completa corretamente.

Se o aluno escolher a letra incorreta, o sistema emitirá o som variando de notas agudas a tons mais graves e a palavra continuará incompleta. Caso o aluno escolha a letra correta, a palavra será completada com a letra escolhida e o som de aplausos será executado.

Após alguns segundos, uma nova imagem será apresentada para o aluno juntamente com a sua palavra correspondente bem como um outro grupo de letras aleatórias, onde uma delas, quando selecionada, irá completá-la adequadamente.

Esse processo se repetirá de acordo com o número de palavras indicadas previamente pelo educador na tela ilustrada pela "Figura 10".

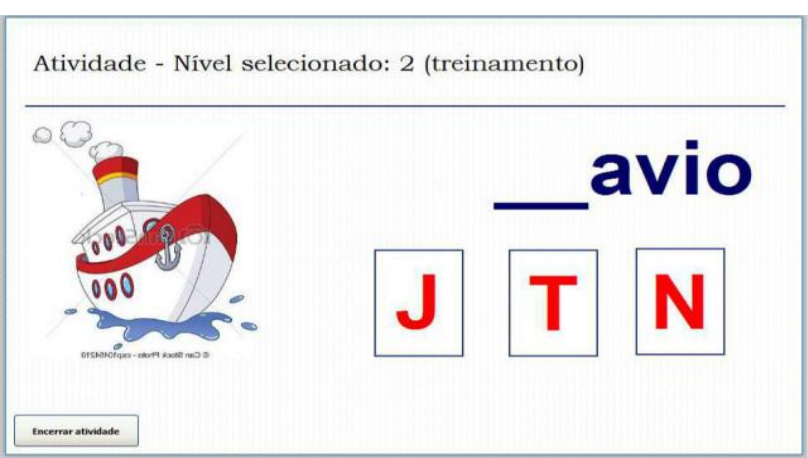

Figura 12: Atividade sendo realizada com o "Nível 2" selecionado.

Fonte: Os autores. 
Ao final da atividade, ilustrada pela "Figura 13 ", o software apresentará o resumo do que foi feito pelo aluno, mostrando o total de palavras acertadas, total de erros, cálculo do percentual de acertos e o tempo total gasto. O resultado poderá ser impresso e, opcionalmente, o educador terá a opção de voltar a tela inicial.

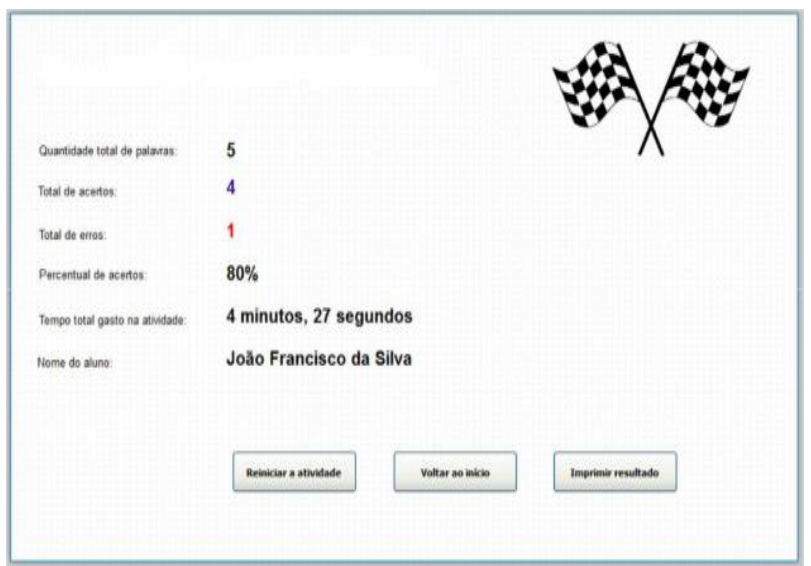

Figura 13: Tela mostrando a finalização da atividade. Fonte: Os autores.

\section{Conclusão}

A educação especial ainda tem necessidade de muitos avanços, mas os que já existem são bastante significativos se comparados, por exemplo, ao início do século XIX, quando as crianças deficientes eram deixadas de lado em qualquer tipo de ocasião social, principalmente em se tratando da educação.

Atualmente, a educação tem tido avanços no que cerne à questão pedagógica e, também, tecnológica na educação especial. Um melhor preparo dos professores e desenvolvimento de tecnologias e materiais didáticos específicos para as deficiências, são de grande valia para o público especial, principalmente as crianças. Porém, ressalvas devem ser feitas. A preparação dos professores se faz em cursos de especialização, sejam de extensão universitária ou de pós-graduação, e quase sempre se dirigem a instituições especializadas de educação especial, o que subtrai a qualidade deste tipo de ensino na educação regular.

A oferta de softwares educacionais voltados à alfabetização de crianças com necessidades especiais é muito limitada. Embora o desenvolvimento de softwares educacionais tenha crescido muito na atualidade, visto que a educação e a informática vêm se fundindo com o interesse de aprimoramento das práticas educacionais. Na área educacional, tanto para crianças especiais, quanto para qualquer criança em fase de alfabetização, os softwares educacionais despertam interesse e sofisticação no acompanhamento de atividades.

Este trabalho foi desenvolvido com o objetivo de fornecer diretrizes básicas e essenciais para se desenvolver um software capaz de auxiliar professores na alfabetização de crianças especiais. Para sua realização, foi seguida uma metodologia embasada em pesquisa de trabalhos semelhantes e acompanhamento de atividades em escolas visitadas.

Em trabalhos futuros, sugere-se a generalização do software de modo que ele atenda a todo o processo de educação do aluno junto com uma avaliação mais ampla, capaz de acompanhar com exatidão suas futuras necessidades, bem como manter sua disponibilização livre a fim de tornar-se conhecido, alcançando e auxiliando o maior número possível de profissionais educadores.

Pode-se afirmar que a utilização de softwares na educação especial tem o objetivo de inclusão, tanto escolar quanto digital.

Trabalhando com os softwares corretos em cada caso, pode-se diminuir a exclusão e mostrar ao mundo que não são apenas padrões físicos que devem ser levados em conta, mais sim éticos, morais e intelectuais. Uma pessoa com necessidades educacionais especiais pode sim realizar muitas tarefas, só que para isso terá muitas vezes a necessidade de uma ferramenta diferente, podendo ser um computador ou outro equipamento digital.

\section{Referências}

[1] SAHB, WARLEY F. A informática na inclusão de pessoas portadoras de necessidades especiais: a síndrome de Down e a Escola Comum. Disponível em: https://www.revistas.ufg.br/fef/article/view/3607 44069

[2] MARINHO, (1998). Educação na era da informação: os desafios na incorporação do computador na escola. Tese de Doutorado [361 p.]. São Paulo: Pontifícia Universidade Católica de São Paulo. 361p. 
[3] SILVA, R. M. F; MEDEIROS, F. R. Aplicação de um programa computacional educativo para os alunos com necessidades especiais que apresentam dificuldades na aprendizagem da leitura e da escrita. In: Fórum de Informática Aplicada a Pessoas Portadoras de Necessidades Especiais, 3., 2004, Itajaí. Anais...

Itajaí:CBCOMP, 2004. p.686-690. Disponível em: http://www.ufrgs.br/niee/eventos/CBCOMP/2004 Lpdf/Forum/t170100301 3.pdf

[4] SILVA, Rosária Maria Fernandes. O efeito de dois procedimentos de sondas de leitura sobre o comportamento de generalização em crianças com dificuldades de aprendizagem. [Dissertação] Universidade Federal de Santa Catarina. Centro de Filosofia e Ciências Humanas. Santa Catarina: o autor, 2000. Disponível em:

https://repositorio.ufsc.br/xmlui/handle/1234567 $\underline{89 / 79277}$

[5] AMATE, Flávio César. Jogos computadorizados para auxiliar a alfabetização de crianças especiais. In: Acessibilidade, TI e Inclusão Digital, 2., 2003, São Paulo. Anais... São Paulo: Universidade de Mogi das Cruzes-MG 2003. Disponível em:

http://www.prodam.sp.gov.br/multimidia/midia/c d atiid/conteudo/ATIID2003/MR3/03/JogosComp utadorAlfabetizacaoCrian.PDF

[6] PETZOLD, Charles. Programming Windows: The definiitie guide to the Win32 API. [s.I.] Microsoft Press, nov. 1998. Disponível em:

http://vulms.vu.edu.pk/Courses/CS410/Downloa ds/Charles\%20Petzold\%20$\% 20$ Programming\%20Windows $\% 20$ \%205th\%20Ed.pdf

[7] ROCHA, Heoísa; BARANAUSKAS, Cecília. Design e avaliação de interfaces humanocomputador. Campinas, SP: NIED/UNICAMP, 2003. Disponível em:

http://www. nied.unicamp.br/?q=content/designe-avaliação-de-interfaces-humano-computador

[8] NIELSE, Jakob. Norman Group Designing Web Usability: The Practice of Simplicity. São Francisco: Peachpit Press, 1999.
[9] PENCIL PROJECT. An open-source GUI prototyping tool that's available for ALL platforms. Disponível em:

http://pencil.evolus.vn 